\title{
Analytical proofs of expected value and variance of the main functions of continuous probability distributions, with examples of their applications
}

\section{Demostraciones analíticas de valor esperado y varianza de las principales funciones de distribuciones de probabilidad continuas, con ejemplos de sus aplicaciones}

\author{
VILLAGÓMEZ-MÉNDEZ, Juan†*， HERRERA-MIRANDA, Miguel Apolonio, HERRERA- \\ MIRANDA, Israel and CASTILLO-MEDINA, Jorge Antonio
}

Cuerpo Académico en consolidación Estadística Aplicada UAGRO-203, LGAC Didáctica de la Probabilidad y Estadística Universidad Autónoma de Guerrero. Facultad de Matemáticas sede Acapulco

ID $1^{\text {st }}$ Author: Juan, Villagómez-Méndez / ORC ID: 0000-0001-8385-8624, CVU CONACYT ID: 111892

ID $1^{\text {st }}$ Coauthor: Miguel Apolonio, Herrera-Miranda / ORC ID: 0000-0003-4857-839X, CVU CONACYT ID: 214836

ID $2^{\text {nd }}$ Coauhtor: Israel, Herrera-Miranda / ORC ID: 0000-0001-8031-797X, CVU CONACYT ID: 299348

ID $3^{\text {rd }}$ Coauthor: Jorge Antonio, Castillo-Medina / ORC ID: 0000-0001-8393-8894, CVU CONACYT ID: 476324

DOI: $10.35429 / J M Q M .2019 .5 .3 .24 .33$

Received July 28, 2019; Accepted November 10, 2019

\begin{abstract}
The present work proposes the design of mathematical problems, which allow the adequate understanding of mathematical concepts of probability for its correct interpretation and later application in the resolution of probabilistic problems. For the development of this work we rely on the theory of didactic situations of Brousseau (1997) and Sadovsky (2005). We believe that new materials and didactic models of this type have great educational potential because they encourage the analysis and understanding of various probability problems (Panizza, 2003). Accurate communication between teachers and students in the approach, interpretation, resolution, and testing of probability problems is of vital importance. The software used for this purpose is the MATHEMATICA program, a tool that facilitates the writing of formulas and calculations, as well as the construction of graphs, through a friendly interface, facilitating the self-taught work of the student and encouraging the development of analysis skills and problem solving. We believe that these materials will contribute to the teaching and learning processes of probability at higher education levels.
\end{abstract}

Continuous Probability Distributions, Expected Value, Variance

\begin{abstract}
Resumen
El presente trabajo propone el diseño de problemas matemáticos, que permitan la adecuada comprensión de conceptos matemáticos de probabilidad para su correcta interpretación y posterior aplicación en la resolución de problemas probabilísticos. Para el desarrollo de este trabajo nos apoyamos en la teoría de situaciones didácticas de Brousseau (1997) y Sadovsky (2005). Creemos que nuevos materiales y modelos didácticos de este tipo tienen un gran potencial educativo porque fomentan el análisis y comprensión de diversos problemas de probabilidad (Panizza, 2003). Es de vital importancia la comunicación precisa entre los profesores y estudiantes en el planteamiento, interpretación, resolución, y comprobación de problemas de probabilidad. El software utilizado para este propósito es el programa MATHEMATICA, herramienta que facilita la escritura de fórmulas y los cálculos, así como la construcción de gráficos, mediante una interfaz amigable, facilitando el trabajo autodidacta del estudiante y fomentando a la vez el desarrollo de las habilidades de análisis y resolución de problemas. Consideramos que estos materiales permitirán coadyuvar en los procesos de enseñanza y aprendizaje de la probabilidad en el nivel de educación superior
\end{abstract}

Distribuciones de probabilidad continuas, Valor esperado, Varianza

Citation: VILLAGÓMEZ-MÉNDEZ, Juan, HERRERA-MIRANDA, Miguel Apolonio, HERRERA-MIRANDA, Israel and CASTILLO-MEDINA, Jorge Antonio. Analytical proofs of expected value and variance of the main functions of continuous probability distributions, with examples of their applications. Journal-Mathematical and Quantitative Methods. 2019. 3-5: 2433

\footnotetext{
* Correspondence to Author (email: villagomez1956@yahoo.com)

$\dagger$ Researcher contributing first author
} 


\section{Introduction}

This paper focuses on the proofs of expected value and variance of the main continuous probability distributions by applying algebraic procedures supported by artifacts. The concepts involved are developed to understand them in a natural, inductive, and deductive way. The teaching of probability and statistics has presented a significant development in the last years due to its increasing application in several fields of science, technology, and social and administrative disciplines.

Many institutions and educational centers in the world devote great efforts to designing and updating specific curricula and materials. Difficulties have been detected in the teaching-learning process of probability and its impact on the quality of education.

For this proposal, we rely on two approaches due to the nature of probability and its application, the first one referring to the Theory of Didactic Situations Brousseau (1997); Sadovsky (2005). Due to its high educational potential and is relevant to this proposal since it seeks the conditions in an environment and analysis of mathematical knowledge, under the hypothesis that they are not built spontaneously (Panizza, 2003). It is based on the premise that knowledge is not transmitted from one person to another, but that the individual constructs his or her knowledge. The role of the teacher is the key to the rigorous design and judicious and appropriate choice of problems.

The second approach referring to the theory of constructivist knowledge guiding this work, under this strategy, we have chosen the problem-solving method, since it allows interaction in concrete and significant situations, stimulating knowledge, know-how and knowhow-to-be, that is, the conceptual, procedural and attitudinal aspects. Thus, students are in a permanent process of acquiring knowledge in all their contexts, since, for constructivism, the most important thing is not the new knowledge itself, but acquiring new skills with it, which allows students to apply what they already know to a new situation. Specifically, we will address algebraic procedures in the proofs of concepts of expected value and variance.

\section{Justification}

Several reasons justify the proposal of this work, the first one is concerned with the teaching work: it is known that the probability topics are of the most complex for the students of all the educational levels; this is also reported by the literature in Statistical Education (Batanero y Godino, 1997). The second is that it is present from the basic level in the probability curriculum in the Mexican education system.

However, students finish their instruction without having acquired the knowledge and understanding of the concepts. Many times certain subjects are not revised, even within curricular guidelines, and when they are, it is done in a procedural rather than conceptual manner. The third is that, just as students have difficulty understanding concepts of probability, teachers have great difficulty in teaching them comprehensively and clearly.

\section{Problem}

This problem is associated with several factors: since there is little research in this field to guide teachers. According to the teaching experience and works presented in different national and international forums, there are not enough didactic resources to support teaching; the textbooks used to teach probability and statistics give more importance to the procedure than to the understanding, and the exploratory approach is reduced.

It is worth mentioning the books by William Mendenhall (2013), M. Mood Alexander (1978); Ronald E. Walpole (2012) only mention functions and their respective parameters but omit detailed proofs, but in the case of George C. Canavos (1988) present some incomplete developments.

Another important aspect is the scarce national bibliography of probability texts in the last years since they are mainly published in their original language such as English, French, German, Russian, Italian, etc. under the environment of their own cultural values and educational systems, from which many of them have been translated and used as basic texts in probability courses here in Mexico, lacking an own identity, so it is important to write texts under our cultural environment. 


\section{Hypothesis}

Competences are created for the solution of mathematical problems of probability by adequately selecting examples that allow for self-learning in the student, which allows for the development of autonomy and security to undertake more complex activities.

\section{Objectives}

To develop in detail the proofs of expected value and variance of the main continuous probability distributions using algebraic procedures supported by mathematical artifices and integration techniques.

\section{Specific Objectives}

That this material is a guide that helps to strengthen and develop capacities and skills, as well as the autonomous character of the student in the process of his or her professional training at a higher level. These include the following:

\begin{tabular}{|c|c|}
\hline & Expressing ideas clearly \\
\hline & Structuring ideas in a logical way \\
\hline & $\begin{array}{l}\text { Structure graphs, tables and diagrams } \\
\text { that help to obtain the desired result. }\end{array}$ \\
\hline & $\begin{array}{l}\text { Use appropriate mathematical language } \\
\text { and representation }\end{array}$ \\
\hline & $\begin{array}{l}\text { Selection of appropriate mathematical } \\
\text { tools (ICTS) }\end{array}$ \\
\hline & $\begin{array}{l}\text { Demonstrate } \quad \text { knowledge } \\
\text { understanding. }\end{array}$ \\
\hline & Apply mathematics in different contexts \\
\hline & Apply problem-solving techniques \\
\hline & $\begin{array}{l}\text { Recognize and explain patterns, where } \\
\text { appropriate }\end{array}$ \\
\hline & Generalize and justify conclusions \\
\hline
\end{tabular}

\section{Theoretical framework}

In this research, where solving analytical problems is a challenge, it is also an opportunity for the student to develop and acquire skills in solving mathematical problems. It is essential to make clear that the development of these skills is the result of personal work, of the practice acquired by solving problems and of reflection on that practice. It is not possible to become a skilled problem solver by merely reading a book, just as it is not possible to become a good sportsman or pianist by merely reading.
However, the knowledge of the appropriate techniques and of the typical mistakes to be avoided can be as useful for the solver as it is for the sportsman or concert musician. It is clear that, in any of the mathematical branches or knowledge, there inevitably arises the part of concepts and practical application, which is usually called "problem," and which varies as time, place, or circumstances go by.

On the other hand, it is known that problem-solving promotes learning, which is why its inclusion in curricula is important, constituting almost an autonomous discipline within mathematical education. Problemsolving is considered essential in mathematics education. Through problem-solving, students experience the scope and usefulness of mathematics in the real world. Throughout one's life, one will encounter problems that must be faced, both inside and outside the school, since the idea of a problem-free life does not exist.

In a lecture given in 1968, George Polya said: "It is well justified that all mathematical texts contain problems. Problems can even be considered as an essential part of mathematics education". Guzmán M. de (1984) commented that "what we should above all provide our students through mathematics is the possibility of acquiring adequate thinking habits for the resolution of mathematical and nonmathematical problems." What use can a few theorems and properties relating to entities with little meaning be to them in their minds if they are then going to leave them there hermetically sealed? Problem-solving has rightly been called the heart of mathematics, for that is the real value that has attracted and still attracts mathematicians of all time.

From the confrontation with adequate problems motivations, attitudes, habits, ideas for the development of tools can arrive, in a word, the life of mathematics. When we solve problems, we learn fundamentally to understand the functioning of our reasoning, to master our moods, and to increase our self-confidence. 


\section{Research Methodology}

Through the technique of analytical reading and reformulation, which consists of making an indepth observation and analysis so that the elements and their essential relationships that are presented implicitly or directly are clearly distinguished, allowing an analytical algebraic development by sequentially performing the verification of a mathematical definition, being a guide in the search for ideas for the solution. In general, this technique leads us to develop a mathematical process using techniques and artifices that allow a new structuring of the problem according to a closer language until the desired result is obtained. This is a process of analysis and synthesis.

We can say that research in this area began by being empirical, not systematized. It was interested almost exclusively in standard problems and restricted to quantifications about problem-solving behavior. Currently, however, it uses a wide range of methods (quantitative and qualitative), covers a broad spectrum of problems, and has a theoretical basis.

Campistrous P. L. and Rizo C. (1996), with great objectivity point out: that the methodological procedures are aimed at the actions to be carried out by the teacher focused mainly on teaching methodology, leaving aside the search for procedures for student action, which leads to observe and reflect on significant aspects such as:

1. The stimulation is indirect

2. The generalized forms of performance in the student are not achieved. They are necessary for life.

3. The problems are focused on developing calculation skills and not as an object of teaching.

4. The difficulty of the problems and their parameters are not very precise, which confuses or makes it impossible to build analogies.

Particularly in the problems of mathematical analysis, the meanings are not adequately worked out.

Likewise, they present a series of techniques that allow us to face the challenges of solving the most complex problems of mathematics.

\section{Type of Research}

We can classify this research as descriptive, characterized by mathematical analysis and the development of techniques and strategies to pose and solve problems where interpretation and verification become relevant in their application.

\section{Theoretical Methods}

Specifically, we will approach algebraic procedures applying mathematical artifices in the development of the proofs of expected value and variance, to process and write this work and enrich it in its technical character, we rely on the software MATHEMATICA, facilitating the capture and mathematical calculations. In order to obtain the proofs, knowledge of algebra, differential, and integral calculus of a higher level is required.

\section{Methodology to be Developed}

Definitions and basic concepts of a discrete random variable:

\section{Expected value:}

$$
\begin{aligned}
& E(X)=\int_{-\infty}^{\infty} x f_{x}(x) d x \ldots \ldots .(1) \\
& \left.\operatorname{Var}(X)=\sum_{x=1}^{N}(X-E(X))^{2} f(X) \ldots . .(2)\right) \\
& \operatorname{Var}(X)=E\left(X^{2}\right)-[E(X)]^{2} \ldots \ldots \ldots .(3)
\end{aligned}
$$

In the following, we present the results of the analytical proofs of expected value and variance of the main continuous probability distributions, which were carried out by resorting to the application of detailed algebraic work and relying on indirect expressions of derivatives and expected value.

\section{Results}

The developments of the expected value and variance proofs are presented below.

The random variable $X$ has a Uniform Continuous Distribution if its density function is:

$$
\begin{gathered}
\mathbf{f}(\boldsymbol{x})=\frac{1}{\boldsymbol{b}-\boldsymbol{a}} \\
\text { Con: }-\infty<\boldsymbol{a}<\infty,-\infty<\boldsymbol{b}<\infty
\end{gathered}
$$




\section{Substituting in (1)}

$E(x)=\int_{a}^{b} x f(x) d x=\int_{a}^{b} x \frac{1}{b-a} d x$

$\frac{1}{b-a} \int_{a}^{b} x d x$

$\frac{1}{b-a} \int_{a}^{b} x d x=$

$\left.\frac{1}{b-a} \frac{x^{2}}{2}\right|_{a} ^{b}=\frac{b^{2}}{2(b-a)}-\frac{a^{2}}{2(b-a)}=\frac{b^{2}-a^{2}}{2(b-a)}$ $=\frac{(b-a)(b+a)}{2(b-a)}=\frac{b+a}{2}$

thus: $E(x)=\frac{b+a}{2}$

\section{Substituting in (1)}

Let: $E\left(x^{2}\right)=\int_{a}^{b} x^{2} f(x) d x=$

$\int_{a}^{b} x^{2} \frac{1}{b-a} d x=\frac{1}{b-a} \int_{a}^{b} x^{2} d x=$

$\left.\frac{1}{b-a} \frac{x^{3}}{3}\right|_{a} ^{b}$

$=\frac{1}{b-a} \frac{b^{3}}{3}-\frac{1}{b-a} \frac{a^{3}}{3}$

$=\frac{b^{3}-a^{3}}{3(b-a)}=\frac{(b-a)\left(a^{2}+a b+b^{2}\right)}{3(b-a)}=\frac{a^{2}+a b+b^{2}}{3}$

\section{Substituting in 2}

$\operatorname{Var}(\mathrm{x})=\mathrm{E}\left(\mathrm{X}^{2}\right)-(\mathrm{E}(\mathrm{X}))^{2}$

$$
\begin{aligned}
& =\frac{a^{2}+a b+b^{2}}{3}-\frac{(b+a)^{2}}{2^{2}}= \\
& =\frac{4\left(a^{2}+a b+b^{2}\right)-3\left(a^{2}+2 \mathrm{ab}+b^{2}\right)}{12}
\end{aligned}
$$

The random variable $\mathrm{X}$ has a Continuous

Normal Distribution if its density function is:

$$
f(x)=\frac{1}{\sqrt{2 \pi \sigma^{2}}} e^{-\frac{1}{2}\left(\frac{x-\mu}{\sigma}\right)^{2}, \mathrm{I}_{(-\infty, \infty)}(x)}
$$

With $-\infty<\mu<\infty,-\infty<\mathrm{x}<\infty$ and $\sigma^{2}>0$

1) Properties:

1.1) It has a bell shape (Gauss).

1.2) It is symmetrical with respect to $x=\mu$.

1.3) It is continuous in: $-\infty<x<\infty$

1.4) The area or probability under the y-curve on the $\mathrm{x}$-axis is equal to 1 .

1.5) $\mathrm{P}[\mathrm{x} \leqslant \mu]=\mathrm{P}[\mathrm{x} \geqslant \mu]=1 / 2$

1.6) $\mathrm{E}[\mathrm{x}]=\mu \quad \operatorname{Var}(\mathrm{x})=\sigma^{2}$

1.7) $\mathrm{P}[\mathrm{x}=\mathrm{a}]=0$

\section{Substituting in 1}

2) Expected value: $E[x]=\int_{-\infty}^{\infty} x f(x) d x=$

$$
\begin{aligned}
\int_{-\infty}^{\infty} \frac{1}{\sqrt{2 \pi \sigma^{2}}} x e^{-\frac{1}{2}\left(\frac{x-\mu}{\sigma}\right)^{2}} d x= \\
=\frac{1}{\sqrt{2 \pi \sigma^{2}}} \int_{-\infty}^{\infty} x e^{-\frac{1}{2}\left(\frac{x-\mu}{\sigma}\right)^{2}} d x
\end{aligned}
$$

Changing the variable:

$$
\begin{gathered}
y=\frac{x-\mu}{\sigma} \\
\Rightarrow x=\sigma y+\mu ; \frac{d x}{d y}=\sigma \Rightarrow d x=\sigma d y
\end{gathered}
$$

Obtaining the limits of the integral, if: $\mathrm{x}=-\infty$ $\Rightarrow \mathrm{y}=-\infty, \quad \mathrm{x}=\infty \Rightarrow \mathrm{y}=\infty$

$$
\begin{gathered}
\Rightarrow \int_{-\infty}^{\infty} \frac{1}{\sqrt{2 \pi \sigma^{2}}} x e^{-\frac{1}{2}\left(\frac{x-\mu}{\sigma}\right)^{2}} d x \\
=\frac{1}{\sqrt{2 \pi \sigma^{2}}} \int_{-\infty}^{\infty}(\sigma y+\mu) e^{-\frac{y^{2}}{2}} \sigma d y= \\
=\frac{1}{\sqrt{2 \pi \sigma}}\left[\sigma \int_{-\infty}^{\infty} y e^{-\frac{y^{2}}{2}} d y+\mu \int_{-\infty}^{\infty} e^{-\frac{y^{2}}{2}} d y\right] \\
=\frac{1}{\sqrt{2 \pi}} \sigma \int_{-\infty}^{\infty} y e^{-\frac{y^{2}}{2}} d y+\frac{1}{\sqrt{2 \pi}} \mu \int_{-\infty}^{\infty} e^{-\frac{y^{2}}{2}} d y
\end{gathered}
$$

In the first integral:

$$
\begin{gathered}
u=-\frac{y^{2}}{2}, \frac{d u}{d y}=y, \quad d u=-y d y \\
\Rightarrow d y=-\frac{d u}{y} \\
\Rightarrow \frac{\sigma}{\sqrt{2 \pi}} \int_{-\infty}^{\infty} \mathrm{ye}^{-\frac{y^{2}}{2}} d y \\
=\frac{\sigma}{\sqrt{2 \pi}} \int_{-\infty}^{\infty}-\mathrm{ye}^{u} \frac{d u}{y}=\frac{-\sigma}{\sqrt{2 \pi}} \int_{-\infty}^{\infty} e^{u} d u \\
=\frac{-\sigma}{\sqrt{2 \pi}} \mathrm{e}^{-\left.\frac{\mathrm{y}^{2}}{2}\right|_{-\infty} ^{\infty}}=\frac{-\sigma}{\left.\sqrt{2 \pi} \mathrm{e}^{-\frac{\mathrm{y}^{2}}{2}}\right|_{-\infty} ^{\infty}=} \\
\frac{-\sigma}{\sqrt{2 \pi} e^{\frac{\infty^{2}}{2}}-\left(\frac{\sigma}{\sqrt{2 \pi}} e^{\frac{-\infty^{2}}{2}}\right.}=\frac{-\sigma}{\sqrt{2 \pi}(\infty)}+\frac{\sigma}{\sqrt{2 \pi}(\infty)}=\frac{\sigma^{\infty}}{\infty}=0
\end{gathered}
$$

From the second integral we make change of variable:

$$
\begin{gathered}
t=\frac{y^{2}}{2}, y=\sqrt{2} \sqrt{t}, \text { donde: } \\
\frac{d y}{d t}=\frac{\sqrt{2}}{2} t^{\frac{-1}{2}}, \mathrm{dy}=\frac{\sqrt{2}}{2} t^{\frac{-1}{2}} \mathrm{dt}
\end{gathered}
$$

And because it is a symmetrical integral, it doubles in the interval $(0, \infty)$.

$$
\begin{aligned}
\Rightarrow & \frac{\mu}{\sqrt{2 \pi}} \int_{-\infty}^{\infty} e^{-\frac{y^{2}}{2}} d y= \\
& \frac{2 \mu}{\sqrt{2 \pi}} \int_{0}^{\infty} e^{-t} \frac{\sqrt{2}}{2} t \frac{-1}{2} d t=\frac{\mu}{\sqrt{\pi}} \int_{0}^{\infty} e^{-t} t^{\frac{-1}{2}} d t
\end{aligned}
$$

VILLAGÓMEZ-MÉNDEZ， Juan, HERRERA-MIRANDA， Miguel Apolonio, HERRERA-MIRANDA, Israel and CASTILLO-MEDINA, Jorge Antonio. Analytical proofs of expected value and variance of the main Antonio. Analytical proofs of expected value and variance of the main
functions of continuous probability distributions, with examples of their applications. Journal-Mathematical and Quantitative Methods. 2019 
Taking to a Gamma function, when

$$
\begin{aligned}
\Gamma\left(\frac{1}{2}\right) & =\sqrt{\pi} \\
\Rightarrow \frac{\mu}{\sqrt{\pi}} \int_{0}^{\infty} e^{-t} t^{\frac{-1}{2}} d t & =\frac{\mu}{\sqrt{\pi}} \int_{0}^{\infty} e^{-t} t^{\frac{1}{2}-1} d t \\
=\frac{\mu}{\sqrt{\pi}} & \Gamma\left(\frac{1}{2}\right)=\frac{\mu}{\sqrt{\pi}} \sqrt{\pi}=\mu
\end{aligned}
$$

Thus: $\mathbf{E}[\mathbf{x}]=\mu$

From ...3. Variance: $\operatorname{Var}(\mathrm{x})=\mathrm{E}\left[\mathrm{x}^{2}\right]-(\mathrm{E}[\mathrm{x}])^{2}$

$$
\begin{array}{rl}
\mathrm{E}\left[\mathrm{x}^{2}\right]=\int_{-\infty}^{\infty} x^{2} & f(x) d x \\
& =\int_{-\infty}^{\infty} x^{2} \frac{1}{\sqrt{2 \pi \sigma^{2}}} e^{-\frac{1}{2}\left(\frac{x-\mu}{\sigma}\right)^{2}} d x
\end{array}
$$

Changing the variable:

$$
\begin{gathered}
y=\frac{x-\mu}{\sigma} \\
\Rightarrow x=\sigma y+\mu ; \frac{d x}{d y}=\sigma \Rightarrow d x=\sigma d y
\end{gathered}
$$

Obtaining the limits of the integral, if: $\mathrm{x}=-\infty$ $\Rightarrow \mathrm{y}=-\infty, \quad \mathrm{x}=\infty \Rightarrow \mathrm{y}=\infty$

$$
\begin{gathered}
\Rightarrow \int_{-\infty}^{\infty}(x)^{2} \frac{1}{\sqrt{2 \pi \sigma^{2}}} e^{-\frac{y^{2}}{2}} \sigma d y \\
=\int_{-\infty}^{\infty}(\sigma y+\mu)^{2} \frac{1}{\sqrt{2 \pi \sigma^{2}}} e^{-\frac{y^{2}}{2}} \sigma d y= \\
=\int_{-\infty}^{\infty}(\sigma y+\mu)^{2} \frac{1}{\sqrt{2 \pi}} e^{-\frac{y^{2}}{2}} d y \\
=\frac{1}{\sqrt{2 \pi}} \int_{-\infty}^{\infty}\left(\sigma^{2} y^{2}+2 \sigma y \mu+\mu^{2}\right) e^{-\frac{y^{2}}{2}} d y= \\
\frac{1}{\sqrt{2 \pi}}\left[\sigma^{2} \int_{-\infty}^{\infty} y^{2} e^{-\frac{y^{2}}{2}} d y+\right. \\
\left.+2 \sigma \mu \int_{-\infty}^{\infty} y e^{-\frac{y^{2}}{2}} d y+\mu^{2} \int_{-\infty}^{\infty} e^{-\frac{y^{2}}{2}} d y\right] \\
=\frac{\sigma^{2}}{\sqrt{2 \pi}} \int_{-\infty}^{\infty} y^{2} e^{-\frac{y^{2}}{2}} d y+ \\
+\frac{2 \sigma \mu}{\sqrt{2 \pi}} \int_{-\infty}^{\infty} y e^{-\frac{y^{2}}{2}} d y+\frac{\mu^{2}}{\sqrt{2 \pi}} \int_{-\infty}^{\infty} e^{-\frac{y^{2}}{2}} d y=
\end{gathered}
$$

Making a variable change in the first integral:

$$
\begin{aligned}
=\frac{y^{2}}{2} & \Rightarrow y^{2}=2 t, y=\sqrt{2} \sqrt{t} \Rightarrow \frac{d y}{d t} \\
= & \frac{\sqrt{2}}{2} t^{\frac{-1}{2}} d y=\frac{\sqrt{2}}{2} t^{\frac{-1}{2} d t}
\end{aligned}
$$

And because it is a symmetrical integral, it doubles in the interval $(0, \infty)$.

$$
\begin{aligned}
\Rightarrow \frac{\sigma^{2}}{\sqrt{2 \pi}} \int_{-\infty}^{\infty} y^{2} & e^{-\frac{y^{2}}{2}} d y= \\
& =\frac{2 \sigma^{2}}{\sqrt{2} \sqrt{\pi}} \int_{0}^{\infty} 2 t e^{-t} \frac{\sqrt{2}}{2} t^{\frac{-1}{2}} d t= \\
& =\frac{2 \sigma^{2}}{\sqrt{\pi}} \int_{0}^{\infty} e^{-t} t^{\frac{1}{2}} d t
\end{aligned}
$$

Taking to a Gamma function, when
December, 2019 Vol.3 No.5 24-33

$$
\begin{aligned}
& \Gamma\left(\frac{3}{2}\right)=\frac{1}{2} \sqrt{\pi}: \\
& \Rightarrow \frac{2 \sigma^{2}}{\sqrt{\pi}} \int_{0}^{\infty} t^{\frac{1}{2}} d t=\frac{2 \sigma^{2}}{\sqrt{\pi}} \int_{0}^{\infty} e^{-t} t^{\frac{3}{2}-1} d t= \\
& =\frac{2 \sigma^{2}}{\sqrt{\pi}} \Gamma\left(\frac{3}{2}\right)=\frac{2 \sigma^{2}}{\sqrt{\pi}} \frac{1}{2} \sqrt{\pi}=\sigma^{2} \\
& \text { Solving the second integral: } \\
& \frac{2 \sigma \mu}{\sqrt{2 \pi}} \int_{-\infty}^{\infty} y e^{-\frac{y^{2}}{2}} d y \\
& U=\frac{-y^{2}}{2}, \frac{d u}{d y}=-y, d u= \\
& =-y d y \Rightarrow-\frac{d u}{y}=d y \\
& \Rightarrow \frac{2 \sigma \mu}{\sqrt{2 \pi}} \int_{-\infty}^{\infty} y e^{-\frac{y^{2}}{2}} d y= \\
& =\frac{2 \sigma \mu}{\sqrt{2 \pi}} \int_{-\infty}^{\infty} y e^{-u}\left(-\frac{d u}{y}\right) \\
& =\frac{2 \sigma \mu}{\sqrt{2 \pi}} \int_{-\infty}^{\infty}-e^{-u} d u= \\
& =\frac{-2 \sigma \mu}{\sqrt{2 \pi}} e^{-\frac{y^{2}}{2} \rho_{-\infty}^{\infty}}=\frac{-2 \sigma \mu}{\sqrt{2 \pi} e^{\frac{y^{2}}{2}} \rho_{-\infty}^{\infty}} \\
& =\frac{-2 \sigma \mu}{\sqrt{2 \pi} e^{\frac{\infty^{2}}{2}}}-\left(\frac{-2 \sigma \mu}{\sqrt{2 \pi} e^{\frac{(-\infty)^{2}}{2}}}\right)= \\
& =\frac{-2 \sigma \mu}{\sqrt{2 \pi} e(\infty)}+\frac{2 \sigma \mu}{\sqrt{2 \pi} e(\infty)}= \\
& =\frac{-2 \sigma \mu}{\infty}+\frac{2 \sigma \mu}{\infty}=0+0=0
\end{aligned}
$$

Making a variable change in the third integral:

$$
\begin{gathered}
\frac{\mu^{2}}{\sqrt{2 \pi}} \int_{-\infty}^{\infty} e^{-\frac{y^{2}}{2}} d y \\
t=\frac{y^{2}}{2} \Rightarrow y^{2}=2 t, \\
y=\sqrt{2} \sqrt{t}, \frac{d y}{d t}=\frac{\sqrt{2}}{2} t^{\frac{-1}{2}}, d y=\frac{\sqrt{2}}{2} t^{\frac{-1}{2}} d t
\end{gathered}
$$

And because it is a symmetrical integral, it doubles in the interval $(0, \infty)$

$$
\begin{aligned}
\Rightarrow \frac{\mu^{2}}{\sqrt{2 \pi}} \int_{-\infty}^{\infty} e^{-\frac{y^{2}}{2}} d y=\frac{2 \mu^{2}}{\sqrt{2 \pi}} \int_{0}^{\infty} e^{-\frac{y^{2}}{2}} d y \\
=\frac{2 \mu^{2}}{\sqrt{2} \sqrt{\pi}} \int_{0}^{\infty} e^{-t} \frac{\sqrt{2}}{2} t^{\frac{-1}{2}} d t \\
=\frac{\mu^{2}}{\sqrt{\pi}} \int_{0}^{\infty} e^{-t} t^{\frac{1}{2}} d t
\end{aligned}
$$

Taking to a Gamma function, when

$$
\begin{gathered}
\Gamma\left(\frac{1}{2}\right)=\sqrt{\pi} \\
\Rightarrow \frac{\mu^{2}}{\sqrt{\pi}} \int_{0}^{\infty} e^{-t} t^{\frac{1}{2}} d t=\frac{\mu^{2}}{\sqrt{\pi}} \int_{0}^{\infty} e^{-t} t^{\frac{1}{2}-1} d t \\
=\frac{\mu^{2}}{\sqrt{\pi}} \Gamma\left(\frac{1}{2}\right)=\frac{\mu^{2}}{\sqrt{\pi}} \sqrt{\pi}=\mu^{2}
\end{gathered}
$$

Returning to the main integral: 


$$
\begin{gathered}
\int_{-\infty}^{\infty}(x)^{2} \frac{1}{\sqrt{2 \pi \sigma^{2}}} e^{-\frac{y^{2}}{2}} \sigma d y \\
\int_{-\infty}^{\infty}(x)^{2} \frac{1}{\sqrt{2 \pi \sigma^{2}}} e^{-\frac{y^{2}}{2}} \sigma d y \\
=\int_{-\infty}^{\infty}(\sigma y+\mu)^{2} \frac{1}{\sqrt{2 \pi \sigma^{2}}} e^{-\frac{y^{2}}{2}} \sigma d y= \\
=\int_{-\infty}^{\infty}(\sigma y+\mu)^{2} \frac{1}{\sqrt{2 \pi \sigma^{2}}} e^{-\frac{y^{2}}{2}} \sigma d y= \\
=\int_{-\infty}^{\infty}(\sigma y+\mu)^{2} \frac{1}{\sqrt{2 \pi}} e^{-\frac{y^{2}}{2}} d y= \\
=\frac{1}{\sqrt{2 \pi}} \int_{-\infty}^{\infty}\left(\sigma^{2} y^{2}+2 \sigma \mathrm{y} \mu+\mu^{2}\right) e^{-\frac{y^{2}}{2}} d y= \\
=\sigma^{2}+0+\mu^{2}, \Rightarrow \mathrm{E}\left[\mathrm{x}^{2}\right]=\sigma^{2}+\mu^{2} \\
\operatorname{Var}(x)=\mathrm{E}\left[\mathrm{x}^{2}\right]-(E[x])^{2}= \\
=\sigma^{2}+\mu^{2}-\mu^{2}=\sigma^{2} \\
\operatorname{Var}(x)=\sigma^{2}
\end{gathered}
$$

Density function Gamma, defined:

$$
\begin{gathered}
(x)=\frac{\lambda^{r}}{\Gamma(r)} x^{r-1} e^{-\lambda x} \\
I_{(0, \infty)}(x), \operatorname{con} \lambda>0 y r>0 \\
\text { Where: } \Gamma(r)=\int_{0}^{\infty} x^{r-1} e^{-x} d x
\end{gathered}
$$

From 1 we substitute Expected value

$$
\begin{gathered}
(x)=\int_{0}^{\infty} \mathrm{xf}(x) d x= \\
=\int_{0}^{\infty} x \frac{\lambda^{r}}{\Gamma(r)} x^{r-1} e^{-\lambda \mathrm{x}} d x \\
=\int_{0}^{\infty} \frac{\lambda^{r}}{\Gamma(r)} x^{r-1+1} e^{-\lambda \mathrm{x}} d x \\
=\frac{\lambda^{r}}{\Gamma(r)} \int_{0}^{\infty} x^{r-1+1} e^{-\lambda \mathrm{x}} d x
\end{gathered}
$$

Making variable change:

$$
\begin{aligned}
y & =\lambda \mathrm{x} \Rightarrow x=\frac{y}{\lambda} \Rightarrow d x=\frac{d y}{\lambda} \\
\Rightarrow & \frac{\lambda^{r}}{\Gamma(r)} \int_{0}^{\infty} x^{r-1+1} e^{-\lambda \mathrm{x}} d x \\
& =\frac{\lambda^{r}}{\Gamma(r)} \int_{0}^{\infty}\left(\frac{y}{\lambda}\right) e^{-y^{r}} \frac{d y}{\lambda} \\
& =\frac{\lambda^{r}}{\Gamma(r)} \int_{0}^{\infty} \frac{y^{r}}{\lambda^{r}} e^{-y} \frac{d y}{\lambda} \\
& =\frac{1}{\lambda \Gamma(r)} \int_{0}^{\infty} y^{r} e^{-y} d y
\end{aligned}
$$

Observation:

$$
\int_{0}^{\infty} y^{r} e^{-y} d y=\int_{0}^{\infty} y^{r+1-1} e^{-y} d y
$$

looks like a Gamma function with $r+1$

$$
\begin{aligned}
\int_{0}^{\infty} y^{r} e^{-y} d y & =\int_{0}^{\infty} y^{r+1-1} e^{-y} d y= \\
& =\Gamma(r+1)
\end{aligned}
$$

$$
\text { If: } \begin{aligned}
\frac{1}{\lambda \Gamma(r)} \int_{0}^{\infty} & y^{r} e^{-y} d y \\
& =\frac{1}{\lambda \Gamma(r)} \int_{0}^{\infty} y^{r+1-1} e^{-y} d y \\
& =\frac{1}{\lambda \Gamma(r)} \int_{0}^{\infty} y^{r} e^{-y} d y \\
& =\frac{\Gamma(r+1)}{\lambda \Gamma(r)}
\end{aligned}
$$

Applying Gamma Properties: $\Gamma(\mathrm{r}+1)=\left(\mathrm{r}+1^{-}\right.$ 1) $\Gamma(\mathrm{r}+1-1)=\mathrm{r} \Gamma(\mathrm{r})$

Thus: $\boldsymbol{E}(\boldsymbol{x})=\frac{\boldsymbol{r}}{\lambda}$

$$
\Rightarrow \frac{\Gamma(r+1)}{\lambda \Gamma(r)}=\frac{r \Gamma(r)}{\lambda \Gamma(r)}=\frac{r}{\lambda}
$$

From equation 3: $\operatorname{Var}(x)=E\left(x^{2}\right)-(E(x))^{2}$

$$
\begin{aligned}
\text { Let: } E\left(x^{2}\right)= & \int_{0}^{\infty} x^{2} f(x) d x \\
& =\int_{0}^{\infty} x^{2} \frac{\lambda^{r}}{\Gamma(r)} x^{r-1} e^{-\lambda \mathrm{x}} d x= \\
& \int_{0}^{\infty} \frac{\lambda^{r}}{\Gamma(r)} x^{r+2-1} e^{-\lambda \mathrm{x}} d x= \\
= & \frac{\lambda^{r}}{\Gamma(r)} \int_{0}^{\infty} \frac{\lambda^{r}}{\Gamma(r)} x^{r+2-1} e^{-\lambda \mathrm{x}} d x
\end{aligned}
$$

Changing the variable:

$$
\begin{gathered}
y=\lambda \mathrm{x} \Rightarrow x=\frac{y}{\lambda} \Rightarrow d x=\frac{d y}{\lambda} \\
\Rightarrow \frac{\lambda^{r}}{\Gamma(r)} \int_{0}^{\infty} x^{r+2-1} e^{-\lambda \mathrm{x}} d x \\
=\frac{\lambda^{r}}{\Gamma(r)} \int_{0}^{\infty}\left(\frac{y}{\lambda}\right)^{r+2-1} e^{-y} \frac{d y}{\lambda}= \\
=\frac{\lambda^{r}}{\lambda \Gamma(r)} \int_{0}^{\infty} \frac{y^{r+2-1}}{\lambda^{r+2-1}} e^{-y} d y
\end{gathered}
$$$$
\begin{aligned}
& =\frac{\lambda^{r}}{\lambda \Gamma(r)} \int_{0}^{\infty} \frac{y^{r+2-1}}{\lambda^{r+1}} e^{-y} d y \\
& =\frac{\lambda^{r}}{\lambda \lambda^{r+1} \Gamma(r)} \int_{0}^{\infty} y^{r+2-1} e^{-y} d y \\
& =\frac{\lambda^{r}}{\lambda^{2} \lambda^{r} \Gamma(r)} \int_{0}^{\infty} y^{r+2-1} e^{-y} d y \\
& =\frac{1}{\lambda^{2} \Gamma(r)} \int_{0}^{\infty} y^{r+2-1} e^{-y} d y=
\end{aligned}
$$

Observation:

$$
\begin{gathered}
\int_{0}^{\infty} y^{r+2-1} e^{-y} d y=\Gamma(r+2) \\
\Rightarrow \frac{1}{\lambda^{2} \Gamma(r)} \int_{0}^{\infty} y^{r+2-1} e^{-y} d y \\
=\frac{\Gamma(r+2)}{\lambda^{2} \Gamma(r)}
\end{gathered}
$$


Applying Gamma Properties:

$$
\begin{aligned}
& \Gamma(\mathrm{r}+2)=(\mathrm{r}+2-1) \Gamma(\mathrm{r}+2-1)=(\mathrm{r}+1) \Gamma(\mathrm{r}+1)=(\mathrm{r}+1) \\
& (\mathrm{r}+1-1) \Gamma(\mathrm{r}+1-1)=\mathrm{r}(\mathrm{r}+1) \Gamma(\mathrm{r}) \\
& \Rightarrow \frac{\Gamma(r+2)}{\lambda^{2} \Gamma(r)}= \\
& \frac{r(r+1) \Gamma(r)}{\lambda^{2} \Gamma(r)}=\frac{r(r+1)}{\lambda^{2}} \\
& \text { Thus: } E\left(x^{2}\right)=\frac{r(r+1)}{\lambda^{2}} \\
& \operatorname{Var}(x)=\mathrm{E}\left(x^{2}\right)-(E(x))^{2} \\
& =\frac{r(r+1)}{\lambda^{2}}-\left(\frac{r^{2}}{\lambda^{2}}\right)= \\
& \frac{\mathrm{r}(r+1)}{\lambda^{2}}-\frac{r^{2}}{\lambda^{2}}=\frac{\mathrm{r}(r+1)-r^{2}}{\lambda^{2}} \\
& =\frac{r^{2}+r-r^{2}}{\lambda^{2}}=\frac{r}{\lambda^{2}} \\
& \text { Thus: } \operatorname{Var}(x)=\frac{r}{\lambda^{2}}
\end{aligned}
$$

A random variable $\mathrm{Y}$ is said to have a beta probability distribution with parameters $\alpha$ and $\beta$ if and only if the density function of $\mathrm{X}$ is

$$
f(x)=\frac{1}{B(\alpha, \beta)} x^{\alpha-1}(1-x)^{\beta-1}, \mathrm{I}_{(0,1)}(x)
$$

with: $\alpha>0$ y $\beta>0$;

Where: $B(\alpha, \beta)=\int_{0}^{1} x^{\alpha-1}(1-x)^{\beta-1} d x$

$$
\text { Properties: } B(\alpha, \beta)=\frac{\Gamma(\alpha) \Gamma(\beta)}{\Gamma(\alpha+\beta)}
$$

$\Gamma(\alpha)=(\alpha-1) \Gamma(\alpha-1)$ and $\Gamma(\alpha)=(\alpha-1)$ ! when $\alpha$ is an integer From 1 we substitute Expected value

$$
\begin{gathered}
E(x)=\int_{0}^{1} \mathrm{xf}(x) d x \\
=\int_{0}^{1} x \frac{1}{B(\alpha, \beta)} x^{\alpha-1}(1-x)^{\beta-1} d x \\
\Rightarrow \frac{1}{B(\alpha, \beta)} \int_{0}^{1} \mathrm{xx}^{\alpha-1}(1-x)^{\beta-1} d x \\
=\frac{1}{B(\alpha, \beta)} \int_{0}^{1} x^{\alpha-1+1}(1-x)^{\beta-1} d x= \\
=\frac{1}{B(\alpha, \beta)} \int_{0}^{1} x^{(\alpha+1)-1}(1-x)^{\beta-1} d x \\
\frac{B(\alpha+1, \beta)}{B(\alpha, \beta)}=\frac{\Gamma(\alpha+1) \Gamma(\beta)}{\Gamma(\alpha+1+\beta)} / \frac{\Gamma(\alpha) \Gamma(\beta)}{\Gamma(\alpha+\beta)} \\
=\frac{\Gamma(\alpha+1) \Gamma(\beta) \Gamma(\alpha+\beta)}{\Gamma(\alpha+1+\beta) \Gamma(\alpha) \Gamma(\beta)} \\
=\frac{\Gamma(\alpha+1) \Gamma(\alpha+\beta)}{\Gamma(\alpha+\beta+1) \Gamma(\alpha)}
\end{gathered}
$$

Making:

$\Gamma(\alpha+1)=(\alpha+1-1) \Gamma(\alpha+1-1)=\alpha \Gamma(\alpha)$

$\Gamma(\alpha+\beta+1)=(\alpha+\beta+1-1) \Gamma(\alpha+\beta+1-1)$ $=(\alpha+\beta) \Gamma(\alpha+\beta)$

$$
\begin{gathered}
\Rightarrow \frac{\Gamma(\alpha+1) \Gamma(\alpha+\beta)}{\Gamma(\alpha+\beta+1) \Gamma(\alpha)} \\
=\frac{\alpha \Gamma(\alpha) \Gamma(\alpha+\beta)}{(\alpha+\beta) \Gamma(\alpha+\beta) \Gamma(\alpha)}=\frac{\alpha}{(\alpha+\beta)} \\
\text { Thus: } \boldsymbol{E}(\boldsymbol{x})=\frac{\alpha}{(\boldsymbol{\alpha}+\boldsymbol{\beta})}
\end{gathered}
$$

From 3 we substitute Variance

$\operatorname{Var}(x)=E\left(x^{2}\right)-(E(x))^{2}$

$$
\begin{gathered}
E\left(x^{2}\right)=\int_{0}^{1} x^{2} \mathrm{f}(x) d x \\
=\int_{0}^{1} x^{2} \frac{1}{B(\alpha, \beta)} x^{\alpha-1}(1-x)^{\beta-1} d x \\
\Rightarrow \frac{1}{B(\alpha, \beta)} \int_{0}^{1} x^{2} x^{\alpha-1}(1-x)^{\beta-1} d x \\
=\frac{1}{B(\alpha, \beta)} \int_{0}^{1} x^{\alpha-1+2}(1-x)^{\beta-1} d x= \\
=\frac{1}{B(\alpha, \beta)} \int_{0}^{1} x^{(\alpha+2)-1}(1-x)^{\beta-1} d x \\
\frac{B(\alpha+2, \beta)}{B(\alpha, \beta)}=\frac{\Gamma(\alpha+2) \Gamma(\beta)}{\Gamma(\alpha+2+\beta)} / \frac{\Gamma(\alpha) \Gamma(\beta)}{\Gamma(\alpha+\beta)} \\
=\frac{\Gamma(\alpha+2) \Gamma(\beta) \Gamma(\alpha+\beta)}{\Gamma(\alpha+2+\beta) \Gamma(\alpha) \Gamma(\beta)} \\
=\frac{\Gamma(\alpha+2) \Gamma(\alpha+\beta)}{\Gamma(\alpha+\beta+2) \Gamma(\alpha)}
\end{gathered}
$$

Making: $\Gamma(\alpha+2)=(\alpha+2-1) \Gamma(\alpha+2-1)$

$=(\alpha+1) \Gamma(\alpha+1)$

$\Gamma(\alpha+\beta+2)=(\alpha+\beta+2-1) \Gamma(\alpha+\beta+2-1)$

$=(\alpha+\beta+1) \Gamma(\alpha+\beta+1)$

$\Gamma(\alpha+1)=(\alpha+1-1) \Gamma(\alpha+1-1)=\alpha \Gamma(\alpha)$

$\Gamma(\alpha+\beta+1)=(\alpha+\beta+1-1) \Gamma(\alpha+\beta+1-1)$

$=(\alpha+\beta) \Gamma(\alpha+\beta)$

$$
\begin{array}{r}
\Rightarrow \frac{\Gamma(\alpha+2) \Gamma(\alpha+\beta)}{\Gamma(\alpha+\beta+2) \Gamma(\alpha)} \\
=\frac{(\alpha+1) \Gamma(\alpha+1) \Gamma(\alpha+\beta)}{(\alpha+\beta+1) \Gamma(\alpha+\beta+1) \Gamma(\alpha)}= \\
=\frac{(\alpha+1) \alpha \Gamma(\alpha) \Gamma(\alpha+\beta)}{(\alpha+\beta+1)(\alpha+\beta) \Gamma(\alpha+\beta) \Gamma(\alpha)} \\
=\frac{\alpha(\alpha+1)}{(\alpha+\beta)(\alpha+\beta+1)}
\end{array}
$$

$$
=\frac{\alpha(\alpha+1)}{(\alpha+\beta)(\alpha+\beta+1)}
$$

Si $\operatorname{Var}(x)=E\left(x^{2}\right)-(E(x))^{2}$

$$
=\frac{\alpha(\alpha+1)}{(\alpha+\beta)(\alpha+\beta+1)}-\left(\frac{\alpha}{(\alpha+\beta)}\right)^{2}=
$$

VILLAGÓMEZ-MÉNDEZ，Juan, HERRERA-MIRANDA， Miguel Apolonio, HERRERA-MIRANDA, Israel and CASTILLO-MEDINA, Jorge Antonio. Analytical proofs of expected value and variance of the main functions of continuous probability distributions, with examples of their applications. Journal-Mathematical and Quantitative Methods. 2019 


$$
\begin{gathered}
=\frac{\alpha(\alpha+1)}{(\alpha+\beta)(\alpha+\beta+1)}-\frac{\alpha^{2}}{(\alpha+\beta)^{2}} \\
=\frac{\alpha(\alpha+1)(\alpha+\beta)^{2}-\alpha^{2}(\alpha+\beta)(\alpha+\beta+1)}{(\alpha+\beta)(\alpha+\beta)^{2}(\alpha+\beta+1)} \\
=\frac{\alpha^{3}+\alpha^{2} \beta+\alpha^{2}+\alpha \beta-\alpha^{3}-\alpha^{2} \beta-\alpha^{2}}{(\alpha+\beta)^{2}(\alpha+\beta+1)}= \\
=\frac{\alpha^{3}+\alpha^{2} \beta+\alpha^{2}+\alpha \beta-\alpha^{3}-\alpha^{2} \beta-\alpha^{2}}{(\alpha+\beta)^{2}(\alpha+\beta+1)} \\
=\frac{\alpha \beta}{(\alpha+\beta)^{2}(\alpha+\beta+1)} \\
=\frac{\boldsymbol{T} \mathbf{T h u s} \operatorname{Var}(\boldsymbol{x})=}{(\boldsymbol{\alpha}+\boldsymbol{\beta})^{2}(\boldsymbol{\alpha}+\boldsymbol{\beta}+\mathbf{1})}
\end{gathered}
$$

\section{Problems}

1. If a skydiver lands at a random point on a straight line between markers A and B, find the probability that she is closer to A than to B. Find the probability that her distance to $\mathrm{A}$ is more than three times her distance to $\mathrm{B}$.

2. A phone call arrives at a random switch within a minute. The switch was fully occupied for 15 seconds within this oneminute period. What is the probability that the call will arrive when the switch has not been fully occupied?

3. According to Zimmels (1983), the particle sizes used in sedimentation experiments often have a uniform distribution. In sedimentation involving mixtures of particles of various sizes, the larger ones prevent the movement of the smaller ones. Therefore, it is important to study the mean and variance of particle sizes. Assume that spherical particles have diameters that are uniformly distributed between .01 and .05 centimeters. Find the mean and variance of the volumes of these particles. (Remember that the volume of a sphere is $\left.(4 / 3) \backslash[\mathrm{Pi}] \mathrm{r}^{\wedge} 3\right)$

4. It was noted that the weekly amount of money spent by a company over a long period of time on maintenance and repairs is normally distributed approximately with an average of $\$ 400$ and a standard deviation of $\$ 20$. If $\$ 450$ is budgeted for the next week, what is the probability that the actual costs will exceed the budgeted amount?

5. It is specified that cables manufactured for use in a computer system must have resistances between .12 and .14 ohms. The actual measured resistances of the cables produced by Company A have a normal probability distribution with a mean of $.13 \mathrm{ohms}$ and a standard deviation of $.005 \mathrm{ohm}$.

a. What is the probability that a cable selected at random from Company A's production will meet the specifications?

6. Assume that a random variable $\mathrm{X}$ has a Beta distribution with $\backslash$ [Alpha]= 1 and $\backslash$ Beta $]=3$,

(a) Determine the mean and median of $\mathrm{X}$

7. If the proportion of a TV brand that requires service during the first year of operation is a random variable that has a Beta distribution with 'Alpha' $=3$ and 'Beta' $=2$, what is the probability that at least $80 \%$ of the new models of this brand sold this year will require service during their first year of operation?

8. In a certain city, daily water consumption (millions of liters) follows approximately a Gamma distribution with $r=2$ and $V[$ Lambda $]=1 / 3$. If the daily capacity of that city is 9 million liters of water, what is the probability that on any given day the water supply will be inadequate?

9. Assume that the time, in hours, needed to repair a heat pump is a random variable $X$ that has a Gamma distribution with the parameters $r=2$ and $\backslash[$ Lambda $]=2$. What is the probability that the next call will require:

a. at most one hour to repair the pump?

10. In a biomedical investigation, it was determined that the survival time, in weeks, of an animal when subjected to certain exposure to Gamma radiation, has a Gamma distribution with $\mathrm{r}=5$ and $\backslash$ [Lambda $]=1 / 10$. 
a. What is the average survival time of a randomly selected animal of the type used in the experiment?

\section{Conclusions}

In this work, concepts and proofs have been presented using clear and detailed language sufficient for a higher-level mathematician, although in other cases not necessarily for one at the level of an engineering area, a biologist, ecologist, or sociologist using statistics. In order for the student to understand the meanings and procedures performed to achieve the proposed objective, this includes the use of the algebraic artifices supported by differential and integral calculus.

\section{Other essential aspects are:}

a. That the student acquires mastery and understanding of the basic concepts of Axiomatic Probability.

b. That the students develop the autonomous character to build and develop logical arguments under proofs.

c. Students are expected to express themselves correctly using the formal language of Mathematics from knowledge already acquired in this work and previous ones.

\section{Suggestions (future work)}

To further enrich this work, we suggest developing proofs using the moment-generating functions as another way to obtain the expressions of expected value and variance of the main probability distributions.

Perform simulations using mathematical software such as R, Matlab, Mathematica, to name a few, simulating the behavior of major probability distributions with examples from real applications.

We suggest applying this approach to groups of higher-level students in order to assess the scope of the approach.

Develop proofs of the mode and median of these distributions presented in this paper.
Batanero, C., Navarro-Pelayo, V., Godino, J. (1997). Effect of the implicit combinatorial model on combinatorial reasoning in secondary school pupils. Educational Studies in Mathematics , 32199

Brousseau, G. (1997). Theory of didactical situations in mathematics. Dordrecht: Kluwer Academic.

Campistrous, P. L. y Rizo, C. C. (1996): Aprende a resolver problemas aritméticos. Cd. De la Habana: Ed. Pueblo y Educación.

George C. Canavos (1988) Probabilidad y Estadística, Aplicaciones y métodos. McGraw Hill/Interamericana de México, S.A de C.V.

Guzmán, M. de (1994): Para pensar mejor. Editorial Pirámide. Madrid

Mendenhall, W., Beaver, R.J., Beaver, B.M. Introduction to Probability and Statistics, 2013, Brooks/Cole CengageLearning.

Mood, A.M., Graybill, F.A. y Boes, D.C. (1974): Introduction to the Theory of Statistics. USA: McGraw Hill

Panizza, M. (2003). Conceptos básicos de la teoría de situaciones didácticas. Buenos Aires: Paidós

Polya, G. (1965): How to solve it. Princenton University Press (Traducción:Cómo plantear y resolver problemas, de Julián Zugazagoitia Ed. Trillas. México) LIBRO

Ronald E. Walpole, Raymond H. Myers, Sharon L. Myers, Keying ye. Probabilidad y Estadística para Ingeniería y Ciencias. PEARSON EDUCACION, Mexico 2012.

Sadovsky, P. (2005). La teoría de situaciones didácticas: Un marco para pensar y actuar $\mathrm{La}$ enseñanza de las matemáticas.: Reflexiones teóricas para la Educación Matemática. Buenos Aires: El Zorzal.

\section{References}

